The Journal of Laryngology \& Otology

http://journals.cambridge.org/JLO

Additional services for The Journal of Laryngology \& Otology:

Email alerts: $\underline{\text { Click here }}$

Subscriptions: $\underline{\text { Click here }}$

Commercial reprints: $\underline{\text { Click here }}$

Terms of use : $\underline{\text { Click here }}$

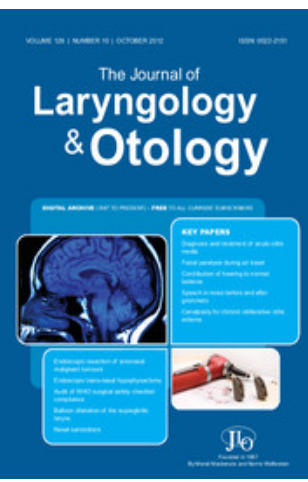

\title{
Treatment of head and neck cancer with photodynamic therapy: results after one year
}

M. G. Dtlkes, M. L. DeJode, Q. Gardiner, G. S. Kenyon and P. McKelvie

The Journal of Laryngology \& Otology / Volume 109 / Issue 11 / November 1995, pp 1072 - 1076

DOI: 10.1017/S0022215100132050, Published online: 29 June 2007

Link to this article: http://journals.cambridge.org/abstract_S0022215100132050

How to cite this article:

M. G. Dtlkes, M. L. DeJode, Q. Gardiner, G. S. Kenyon and P. McKelvie (1995). Treatment of head and neck cancer with photodynamic therapy: results after one year. The Journal of Laryngology \& Otology, 109, pp 1072-1076 doi:10.1017/ S0022215100132050

Request Permissions : $\underline{\text { Click here }}$ 


\title{
Treatment of head and neck cancer with photodynamic therapy: results after one year
}

\author{
M. G. Dilkes, F.R.C.S.(Ed.), F.R.C.S., M. L. DeJode, Ph.D., Q. Gardiner, F.R.C.S., \\ G. S. Kenyon, M.D., F.R.C.S., P. McKelvie, M.D., F.R.C.S.
}

\begin{abstract}
Photodynamic therapy (PDT) is a new and promising treatment modality for the treatment of malignant disease. This paper reports the preliminary experience of our group in the use of this therapy for the treatment of tumours arising in the head and neck. The majority of treatments in these cases have used a second generation systemic photosensitizer, meta-tetrahydroxyphenylchlorin ( $m$-THPC). Two other cases were treated with either Photofrin 2 (a first generation systemic sensitizer) or with the topical photosensitizer, delta-aminolaevulinic acid ( $\delta$-ALA).

The initial results have been encouraging with good clinical responses evident in patients presenting with a variety of differing tumour types. We feel there is now sufficient evidence of the efficacy of this treatment to warrant a multicentre prospective study into the treatment of early head and neck cancer with PDT.
\end{abstract}

Key words: Head and neck neoplasms; Photochemotherapy

\section{Introduction}

A low morbidity alternative form of treatment for malignancy arising in the head and neck is highly desirable. The current standard methods of treatment for cancer in this area comprise radiotherapy and surgery in varying combinations. Both of these are associated with a significant morbidity and the overall mortality rates for anything other than early disease remains high. Moreover surgery in this area is often both aesthetically and functionally disabling (especially if it requires wide excision in order to gain tumour clearance) and radiotherapy carries with it the risks of disabling side effects including xerostomia, mucositis, loss of taste and smell, laryngeal dysfunction and skin erythema: in some instances skin breakdown or osteoradionecrosis may also ensue (Johansen et al, , 1990).

Photodynamic therapy (PDT) was used initially as a diagnostic modality (Lipson et al., 1961). The first clinical therapeutic studies on primary cancer were performed by Kelly and Snell (1976) but these introductory trials were dogged by the use of relatively impure and inefficient drugs haematoporphyrin derivative $(\mathrm{HpD})$ and Photofrin 2 (Lederle Laboratories, Gosport, Hants, UK). Both these early agents required large drug and high light doses to achieve a satisfactory clinical effect and this, in turn, led to prolonged skin light sensitivity. Despite these problems a significant amount of success was achieved in the treatment of head and neck squamous cell carcinomas, particularly in cases of early disease (Gluckman, 1991). The more recently derived drugs, refined from the active components of these early agents, have been shown to have significant advantages over these initial compounds (Berenbaum et al., 1989).

The drugs are usually given either intravenously. or orally, although a newer compound (deltaaminolaevulinic acid: $\delta$-ALA) has also been administered topically. This drug is made from laboratory $\delta$-ALA, in a 20 per cent cream with Unguentum (Merck). Following administration the drugs accumulate within cells sparing the nucleus and, for reasons that are unknown, there is preferential take up by malignant tissue (Dougherty, 1989). While a minimum concentration of photosensitizer in tissue needs to be present before a cytotoxic photodynamic effect will occur there can, theoretically, be complete sparing of normal tissue if drug levels in normal tissue are below the threshold for effect whilst they are above this same threshold in the malignant cell. This is of importance clinically for the timing of delivery of the light stimulus following drug delivery will directly affect both the normal tissue reaction and the tumoricidal effect. However careful attention to this can allow effective treatment of the malignancy with insignificant damage to normal structures (Chevretton, 1993). 


\section{ABSORPTION CHARACTERISTICS}

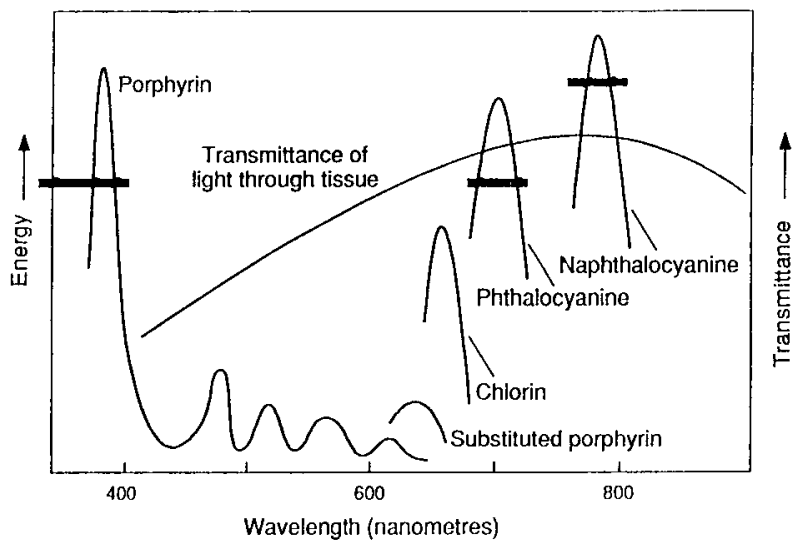

FIG. 1

The amount of light passing through human tissue $1 \mathrm{~cm}$ thick, related to absorption by porphyrins.

The exact mode of action of the drug after light activation is unknown but appears to involve the transformation of the drug to a higher energy state at the cellular level. In the subsequent decay from this higher level to the normal steady state free radicals such as superoxide ions are formed. These substances oxidize any adjacent biological structures and, within a cell, this leads to destruction of vital organelles - with cell death (Weishaupt et al., 1976). The wavelength of light used to activate the photosensitizing drug is critical to the depth of the photodynamic effect because light of different wavelengths penetrates tissues to different degrees.

Peaks of penetration occur at a wavelength of around 850 nanometres (nm) (Figure 1), and newer photosensitizing drugs have therefore been designed to have a high absorption peak at or around this wavelength (Bonnet and Berenbaum, 1989).

In this paper we report a series of patients in whom such second generation photosynthesizers have been used either as primary or as adjunctive treatment in patients with head and neck malignancy, along with our early experience using two other photosensitizing drugs.

\section{Material and methods}

Over the course of the 12 months between December 1992 and December 1993 a series of 17 treatments were given to patients selected for photodynamic therapy (PDT) on a case by case basis. Selection was by consultant ENT surgeons and radiotherapists. Those included were patients who were not thought to be suitable for standard treatment or those in whom adjunctive treatment was thought to be potentially beneficial.

Full informed consent was obtained with particular attention being paid to warning patients of the dangers of light exposure following drug administration. It was decided that both doctors and nurses should be involved in this counselling and the treatment would not be offered if any patients were thought to be at risk of not understanding or complying with the necessary protocols. In practice no patient was withdrawn for this reason.

We used a particularly active systemic photosensitizer, meta-tetrahydroxyphenylchlorin ( $m$-THPC) for 15 treatments. The advantages of this drug over $\mathrm{HpD}$ and Photofrin 2 have been outlined in the introduction and are presented in Table I. In one early case Photofrin 2 was used because we did not feel familiar enough with $m$-THPC at this stage to use it clinically: in one other case we used a topically active photosensitizing drug, $\delta$-ALA, for a patient with an early skin cancer. The patients treated are detailed in Table II.

Following drug administration a copper vapour laser pumping a rhodamine dye laser (Oxford Lasers, Abingdon Rd, Oxford, UK) was employed to activate the drug. The wavelength used was 652 nanometres $(\mathrm{nm})$ for $m$-THPC and $630 \mathrm{~nm}$ for $\delta$-ALA and Photofrin 2. These wavelengths corresponded with the peak of light absorption in the red band for each compound and ensured maximal tissue penetration. Light was delivered down a 600 micron quartz fibre into a microlens (QLT, Vancouver, Canada), a cylinder diffuser (PDT systems, San Jose, California, USA) or a freshly cleaved bare fibre depending on the site of the tumour. In all cases using $m$-THPC the interval between drug and light administration was 96 hours, the energy density was 100 milliwatts per square centimetre $\left(\mathrm{mW} / \mathrm{cm}^{2}\right)$ and the total light dose was 20 Joules per square centimetre $\left(\mathrm{J} / \mathrm{cm}^{2}\right)$. Light was delivered to the tumour so that the angle of incidence was close to $90^{\circ}$, and care was taken to ensure that the distribution over the irradiated area was as even as possible. With Photofrin 2 the drug-light interval was 48 hours and the equivalent of $50 \mathrm{~J} / \mathrm{cm}^{2}$ was applied interstitially to the tumour. In the sole case in which

TABLE I

\begin{tabular}{lll}
\hline & Photofrin $2 / \mathrm{HpD}$ & $m$-THPC \\
\hline Purity & Difficult to purify & $99 \%$ purity available \\
Assay & Several active components, therefore difficult to assay & Single component, easily measured \\
Efficiency & Only moderate, therefore high drug and light doses & High efficiency, in the order of $100 \times$ greater \\
& needed & than Photofrin \\
Specificity & $\begin{array}{l}\text { Studies show approximately } 2: 1 \text { tumour to normal } \\
\text { tissue ratio }\end{array}$ & Available data shows around 6:1 tumour to \\
Red spectrum peak & 630 nm & 652 nm tissue ratio \\
Solubility & Difficult to dissolve & Easy to dissolve \\
\hline
\end{tabular}


ס-ALA was utilized the drug was applied as a cream to the tumour site once excess surface skin cells had been removed with scraping and adhesive tape. The cream was left on the tumour for three hours following which EMLA anaesthetic cream was applied for one hour prior to light treatment being given at $150 \mathrm{~J} / \mathrm{cm}^{2}$ with an energy density of $150 \mathrm{~mW} /$ $\mathrm{cm}^{2}$.

Tumour response was graded using a modification of the World Health Organization system: (1) ? Complete. No evidence of tumour macroscopically during two inspections of the treatment site one month apart, with a negative biopsy after 12 weeks. (2) Good. Macroscopic response of tumour, with reduction in tumour bulk to 50 per cent of the original size at four weeks. (3) Moderate. Macroscopic response of tumour, with some reduction in tumour bulk at four weeks. (4) Poor. No obvious response of tumour.

\section{Results}

All of the treatments resulted in the tumour visibly responding to the effects of PDT (see Table II). This ranged from mild sloughing in the one case where a poor response occurred (treatment no. 3), to significant and prolonged sloughing over a period up to four weeks. Large reactions to the therapy were characterized by a necrotic smell, which was treated successfully with oral metronidazole therapy. The topical treatment with $\delta$-ALA resulted in erythema of the tumour and some surrounding skin, followed by a scab formation and regression of the neoplasm: however this was incomplete. In those cases where pain was the most significant symptom (treatment nos. 1, 2 and 9), there was undoubtedly a reduction in the levels of analgesia needed after treatment.

Minor complications did occur. In all cases where $m$-THPC PDT was used there was local pain in the arm following the slow intravenous injection of the drug. This lasted for up to three minutes and was

TABLE II

\begin{tabular}{|c|c|c|c|c|c|c|}
\hline No. & Description & Cell & TNM & $\mathrm{FU}$ & Dose & Response \\
\hline 1 & $\begin{array}{l}\text { Pyriform fossa post-DXT. } \\
\text { Inoperable due to mental state }\end{array}$ & $\mathrm{SCC}$ & $\mathrm{T}_{2}$ & 6 & $1.5 \mathrm{PF} 2$ & $\begin{array}{l}\text { Good. Died with residual } \\
\text { tumour }\end{array}$ \\
\hline 2 & $\begin{array}{l}\text { Tonsil/floor of mouth. Post-DXT } \\
\text { and surgery }\end{array}$ & $\mathrm{SCC}$ & $\begin{array}{l}\mathrm{T}_{4} \\
\mathrm{~N}_{0}\end{array}$ & 12 & 0.3 & $\begin{array}{l}\text { Good. Died with residual } \\
\text { tumour }\end{array}$ \\
\hline 3 & $\begin{array}{l}\text { Post-nasal space/posterior } \\
\text { faucial pillar. Post-DXT }\end{array}$ & SCC & $\begin{array}{l}\mathrm{T}_{3} \\
\mathrm{~N}_{0}\end{array}$ & 7 & 0.15 & Poor. Lost to follow-up \\
\hline 4 & Pyriform fossa & $\mathrm{SCC}$ & $\begin{array}{l}T_{2} \\
N_{0}\end{array}$ & 22 & 0.15 & ? Complete \\
\hline 5 & Soft palate & $\mathrm{SCC}$ & $\begin{array}{l}\mathrm{T}_{2} \\
\mathrm{~N}_{0}\end{array}$ & 20 & 0.15 & ? Complete \\
\hline $6^{*}$ & Tongue base & $\mathrm{MM}$ & $\begin{array}{l}\mathrm{T}_{2} \\
\mathrm{M}_{1}\end{array}$ & 2 & 0.15 & Good \\
\hline $7^{*}$ & Tongue base & MM & $\begin{array}{l}\mathrm{T}_{2} \\
\mathrm{M}_{1}\end{array}$ & 1 & 0.15 & Moderate \\
\hline $8^{*}$ & Tongue base & MM & $\begin{array}{l}\mathrm{T}_{2} \\
\mathrm{M}_{1}\end{array}$ & 12 & 0.15 & ? Complete \\
\hline 9 & $\begin{array}{l}\text { Tongue base/pyriform fossa. } \\
\text { Post-DXT + surgery }\end{array}$ & SCC & $\begin{array}{l}\mathrm{T}_{4} \\
\mathrm{~N}_{0}\end{array}$ & 4 & 0.3 & Good. Died at 6 months \\
\hline 10 & Aryepiglottic fold (2nd primary) & $\mathrm{SCC}$ & $\begin{array}{l}\mathrm{T}_{2} \\
\mathrm{~N}_{0}\end{array}$ & 7 & 0.15 & $\begin{array}{l}\text { ? Complete. Died of CVA at } 7 \\
\text { months }\end{array}$ \\
\hline $11^{+}$ & Glottis/supraglottis & $\mathrm{VCC}$ & $\mathrm{T}_{2}$ & 2 & 0.15 & Good \\
\hline $12^{+}$ & Glottis & $\mathrm{VCC}$ & $\mathrm{T}_{1}$ & 2 & 0.15 & Good \\
\hline $13^{+}$ & $\begin{array}{l}\text { Glottis (laryngofissure } \\
\text { AIOPDT) }\end{array}$ & $\mathrm{VCC}$ & $T_{1}$ & 1 & 0.15 & ? (DXT given) \\
\hline 14 & $\begin{array}{l}\text { Neck (after neck dissection } \\
\text { AIOPDT) }\end{array}$ & SCC & $\mathrm{N}_{2}$ & 1 & 0.15 & Died at $6 / 52$ no residual disease \\
\hline 15 & $\begin{array}{l}\text { Neck (after neck dissection - } \\
\text { tumour on carotid, AIOPDT) }\end{array}$ & $\mathrm{SCC}$ & $\mathrm{N}_{3}$ & 2 & 0.15 & Local recurrence \\
\hline 16 & $\begin{array}{l}\text { Maxilla (after maxillectomy, } \\
\text { AIOPDT) }\end{array}$ & $\mathrm{SCC}$ & $\mathbf{T}_{4}$ & 4 & 0.15 & $\begin{array}{l}\text { No local recurrence at area } \\
\text { treated }\end{array}$ \\
\hline 17 & Nose (recurrence after surgery) & $\mathrm{BCC}$ & $\mathrm{T}_{1}$ & 2 & Cream $\delta$-ALA & Local recurrence \\
\hline
\end{tabular}

$\mathrm{SCC}=$ Squamous cell carcinoma. $\mathrm{VCC}=$ Verrucous carcinoma. $\mathrm{MM}=$ Malignant melanoma. $\mathrm{BCC}=$ Basal cell carcinoma. $\mathrm{FU}=$ follow-up in months. DXT = radiotherapy. AIOPDT = Adjunctive intraoperative PDT.

All doses are in $\mathrm{mg} / \mathrm{kg}$ and represent $m$-THPC intravenously except where stated. $\delta$-ALA $=$ delta-aminolaevulinic acid applied topically. PF2 = Photofrin 2 intravenously.

*One patient, three sequential treatments at monthly intervals.

${ }^{+}$One patient, three sequential treatments at six weekly intervals. 
thought to be due to the irritant effect of the dilutant on the veins. Post-operative pain was also present in all cases. It tended to start 24 hours after treatment and last between two and three weeks. In no case were patients unable to swallow fluids although some required generous analgesia and could not eat solid food for up to one week. In addition a very mild photosensitive reaction occurred in the second case after the second treatment when the patient, who was observing all reasonable precautions, sat in front of a log fire for several hours one evening seven days after drug administration. The ensuing minor oedema of the lower eyelid and the back of the hands lasted approximately four days.

There were no other adverse effects in any of the other cases treated. Those cases that could be followed closely showed an initial slough developing over the treatment site. This came on after approximately 24 hours, and stayed for up to three weeks. After five days, however, the slough was only at the tumour site, the surrounding non-tumour tissue in the treatment area having undergone mild erythema and slough formation before returning to normal.

In two cases sequential treatments were given. In the first of these cases (treatment nos. 6, 7, and 8) the patient suffered with secondary malignant melanoma and presented with a deposit on the posterior third of the tongue. The tumour was approximately $3 \mathrm{~cm}$ in diameter. Chemotherapy had failed, radical surgery was clearly inappropriate and radiotherapy was held to be ineffective in this disease. A good, but not complete, tumour regression was achieved with the first procedure and, when macroscopic evidence of further disease was seen, second and third treatments were offered. All visible tumour regressed and a full resolution of symptoms was achieved. Twelve months later the patient remains macroscopically free of tumour and symptom free.

In the second case multiple treatments (treatment nos. 11, 12 and 13) were performed for a different reason. On laryngoscopy and biopsy of this patient verrucous laryngeal carcinoma was reported. Photodynamic therapy was felt to be attractive since the entire area could be treated uniformly with a single spot of laser light. The patient in question was extremely difficult to endoscope. Unfortunately, despite a good macroscopic reaction of the tumour to treatment, full regression did not occur: this was thought to be due to inadequate light delivery and a second treatment with a different method of delivery also failed due to the difficult access. A third attempt was made using photodynamic therapy adjunctively after a laryngofissure and superpulse carbon dioxide excision of the tumour. In fact histology then showed invasive squamous cell carcinoma (SCC) rather than the previously reported verrucous tumour. Radical radiotherapy was therefore subsequently given.

In neither of these cases was any adverse reaction seen from the effects of cumulative therapy.

\section{Discussion}

The use of photodynamic therapy seems to offer a new and useful method of treating and palliating patients with malignancy in the head and neck. In particular $m$-THPC seems to have a great deal of potential for use at this site. This compound has a strong absorption peak at $652 \mathrm{~nm}$ - giving it a better depth of penetration than Photofrin 2 or $\delta$-ALA and it has a much greater degree of superoxide generation for a given amount of delivered light energy. This makes the light and drug doses required for effective action much smaller. Thus a typical dose of this drug is only $0.15 \mathrm{mg} / \mathrm{kg}$ as compared with 1.0 to $2.0 \mathrm{mg} / \mathrm{kg}$ used for Photofrin 2 and, in turn, the smaller amount of drug halves the time that patients need to avoid bright sunlight from two months to one. This is difficult to confirm on a molecular basis however, since the relative molecular mass of Photofrin 2 is unknown, due to its exact make up being unknown. Moreover the light dose needed for efficient tumour death with $m$-THPC is also smaller: only $20 \mathrm{~J} / \mathrm{cm}^{2}$ is required compared to $50-100 \mathrm{~J} / \mathrm{cm}^{2}$ for Photofrin 2 and $150 \mathrm{~J} / \mathrm{cm}^{2}$ for $\delta$-ALA. This has the benefit of reducing treatment times. The differences between the second and first generation drugs is summarized in Table $\mathrm{I}$.

The intensity of light delivery is limited by the fibre end output of the copper vapour/rhodamine laser system. Because treatment areas are often around $10 \mathrm{~cm}^{2}$, this limits the light intensity to 100 $\mathrm{mW} / \mathrm{cm}^{2}$ since the maximum output of the laser is around $1 \mathrm{~W}$ in the red spectrum. Whether a better effect occurs at higher or lower light intensities is currently unknown, although above $300 \mathrm{~mW} / \mathrm{cm}^{2}$ an undesirable heating effect will probably occur even from simple surface illumination.

With new laser systems such as the Laserscope KTP pumped dye laser (Laserscope UK, Raglan House, Cwmbran, Gwent) power outputs from the end of a fibre at $652 \mathrm{~nm}$ can be up to $7 \mathrm{~W}$, making the treatment of larger areas far quicker and easier to perform.

In this study the drug doses given with Photofrin 2 and $\delta$-ALA were in accordance with previously recommended treatment protocols (G. Stables, personal communication). For treatment using $m$-THPC drug doses of either $0.3 \mathrm{mg} / \mathrm{kg}$ or 0.15 $\mathrm{mg} / \mathrm{kg}$ were used: the lower dose, which seems equally effective, is now preferred since it reduces problems with skin sensitivity. The light parameters used were chosen on the basis of experimental work (Ris et al., 1993; Dilkes, 1995) as was the time delay between drug and light administration. Current research is aimed at further reducing the drug dose of $m$-THPC and increasing the light fraction while ensuring continued clinical efficacy.

Because malignant melanoma may regress spontaneously it may be that the inflammatory reaction set up in the tumour during treatment (treatment nos. 6,7 and 8) was enough to stimulate an otherwise quiescent immune response. However the case demonstrates that the sequential administration of photodynamic therapy is possible. It also illustrates that tumours deeper than $1 \mathrm{~cm}$ can be successfully treated since sequential treatments in this case, 
which involved a substantial depth of the tongue, led to the eventual disappearance of the tumour. Therefore photodynamic therapy might also be useful for later disease which recurs locally after surgery and radiotherapy.

Delta-aminolaevulinic acid ( $\delta$-ALA) is a different form of compound from the more classical photosensitizers. It acts by being rapidly metabolized into an active photosensitizing agent, protoporphyrin 9 (PP9) which is then slowly metabolized into haem (a rate-limiting step). Active photosensitization only occurs during a fairly short period of time when PP9 levels are high and this obviates problems with skin sensitization if applied topically. However due to its relative inefficiency compared to $m$-THPC it can only be used to treat very superficial lesions such as early basal cell carcinoma. While the amount of light needed for a good clinical effect appears to be circa $150 \mathrm{~J} / \mathrm{cm}^{2}$, which increases the treatment time compared to $m$-THPC, the fact that it is effective topically is enough to make this a very exciting compound for full scale clinical use. However as the case presented here illustrates (treatment no. 17), it is only useful for the most superficial of lesions. While an intense tumour reaction to treatment was seen clinically in this case the neoplasm was, presumably, too deep for a curative effect to have been achieved.

While primary therapy of early cancers is thought to be one of the most encouraging areas of PDT treatment (Monnier et al., 1990), adjunctive therapy also seems to have exciting possibilities. Such treatment could theoretically be used during surgery in the expectation that microscopic tumour residue will be eradicated. Animals studies have shown that the local recurrence of tumours after resection can be reduced by up to 50 per cent with adjunctive PDT (Davis et al., 1990; Dilkes, 1995). Safety work on the effects of $m$-THPC PDT on arteries has shown it to be safe when the drug and light doses and drug-light time intervals outlined are observed (Dilkes, 1995).

We have no experience that we can report of reducing tumour bulk prior to surgical resection but we have successfully given photodynamic therapy during surgery in three cases. Such intraoperative therapy has been used with no adverse effects even when treatment was delivered directly to the carotid artery as part of a radical neck dissection (treatment nos. 14 and 15 ).

Due to the small numbers and relatively short period of follow-up it is not possible to make any definite claims as to the efficacy, or not, of this form of treatment for head and neck cancer. There is no doubt that it offers a low morbidity form of treatment for this condition however. We feel that the results presented here are encouraging particularly with respect to the treatment of early malignancy with $m$-THPC PDT. We have instigated a multicentre study looking at the primary treatment of selected cases of head and neck mucosal malignancy. Although there have been several small series describing good results with this form of therapy, no large multicentre trial has yet been conducted either with the older or the newer drugs. PDT appears to have few side effects and is easily administered either as primary or adjunctive therapy. In addition treatment can be repeated with safety in the same patient.

\section{References}

Berenbaum, M. C., Akande, S. L., Bonnet, R., Kaur, H., Ioannou, S., White, R. D., Winfield, U.-J. (1989) Meso-tetra (hydroxyphenyl)porphyrins, a new class of potent tumour photosensitizers with favourable selectivity. British Journal of Cancer 54: 717-725.

Bonnet, R., Berenbaum, M. C. (1989) Porphyrins as photosensitizers. In Photosensitizing Compounds: their Chemistry, Biology and Clinical use. (CIBA Foundation Symposium 146). Wiley, Chichester, pp 40-59.

Chevretton, E. B. (1993) M.S. Thesis, London University.

Davis, R. K., Smith, L. F., Thurgood, R. F., Kereszti. Z. Straight, R. C. (1990) Intraoperative phototherapy (PDT) and surgical resection in a mouse neuroblastoma model. Lasers in Surgery and Medicine 10: 275-279.

Dilkes, M. G. (1995) M.S. Thesis, London University in press.

Dougherty, T. J. (1989) Photodynamic therapy - new approaches. Seminars in Surgical Oncology 5: 6-16.

Gluckman, J. L. (1991) Hematoporphyrin photodynamic therapy: is there truly a future in head and neck oncology? Reflections on a 5-year experience. Laryngoscope 101: $36-41$.

Johansen, L. V., Overgaard, J., Overgaard, M., Birkler. N. Fisker, A. (1990) Squamous cell carcinoma of the oropharynx: an analysis of 213 consecutive patients scheduled for primary radiotherapy. Laryngoscope 100: 985-990.

Kelly, J. F., Snell, M. E.(1976) Hematoporphyrin derivative: a possible aid in the diagnosis and therapy of carcinoma of the bladder. Journal of Urology 115: 150-151.

Lipson, R., Baldes, E., Olsen, A. (1961) The use of a derivative of hematoporphyrin in tumour detection. Journal of the National Cancer Institute 26: 1-8.

Monnier, Ph., Savary, M., Fontolliet, Ch., Wagnieres, G.. Chatelain, A., Cornaz, P., Depeursinghe, Ch., Van den Burgh, H. (1990) Photodetection and photodynamic therapy of "early SCC of the pharynx, oesophagus and tracheobronchial tree'. Lasers in Medical Science 5: 149-169.

Ris, H. B., Altermatt, H. J., Stewart, C. M., Schaffner. T., Wang, Q., Lim, C. K., Bonnet, R., Aldhaus, U. (1993) Photodynamic therapy with $m$-tetrahydroxyphenylchlorin in vivo: optimization of the therapeutic index. International Journal of Cancer 55: 245-249.

Weishaupt, K. R., Gomer, C. J., Dougherty, T. J. (1976) Identification of singlet oxygen as the cytotoxic agent in photoinactivation of a murine tumour. Cancer Research 36: 2326-2329.

Address for correspondence:

Mr M. G. Dilkes, F.R.C.S.(Ed.), F.R.C.S.

64, Wembley Park Drive,

Wembley Park,

Middlesex HA9 8HB.

Fax: 01819020003 